\title{
Sintesis Turunan 2'-hidroksi Kalkon melalui Kondensasi Claisen-Schmidt dan Uji Aktivitasnya sebagai Antimikroba
}

\author{
Yum Eryanti*), Adel Zamri, Jasril dan Rahmita \\ Laboratorium Kimia Organik Sintesis, Jurusan Kimia FMIPA Universitas Riau Kampus Bina Widya \\ Jl. HR.Soebrantas KM 12,5 Pekanbaru 28293
}

Diterima 14-04-2009

Disetujui 12-12-2009

\begin{abstract}
ABSTRAK
Tiga senyawa turunan kalkon telah berhasil disintesis dari suatu keton aromatik dan aldehida aromatik melalui reaksi kondensasi Claisen-Schmidt dalam suasana basa. Turunan kalkon tersebut adalah 2'-hidroksi kalkon, (2Z,4Z)-1-(2-hidroksifenil)-5-fenilpenta-5-2-4-dien-1-on dan 2'-hidroksi-4-dimetilamino kalkon. Senyawa yang dihasilkan relatif murni, dilihat dari uji KLT yang menunjukkan satu noda dan titik leleh ketiganya berada pada range kecil. Elusidasi struktur didasarkan pada data spektra UV, IR, ${ }^{1} \mathrm{H}-\mathrm{NMR}$ dan ${ }^{13} \mathrm{C}-\mathrm{NMR}$. Uji antimikroba terhadap ketiga senyawa, hanya satu senyawa yang memberikan hasil positif yaitu senyawa 2'-hidroksi-4-dimetilamino kalkon pada konsentrasi 60 ig terhadap bakteri B.subtilis.
\end{abstract}

Keyword: antimicrobial, Claisen-Schmidt, kalkon

\section{PENDAHULUAN}

Senyawa turunan kalkon merupakan salah satu tipe metabolit sekunder yang termasuk dalam golongan flavonoid. Beberapa diantara turunan kalkon dilaporkan mempunyai keaktifan biologi sebagai antifungi, antibakteri (Alam 2004), antikanker dan antitumor (Hayashi et al., 2000, Usman et al., 2005), antiinflamansi, antimutagenik dan antialergi (Vender et al, 1993). Likokalkon yang diisolasi dari akar Licorice, Glycyrrhiza inflata digunakan dalam industri rokok, industri makanan, industri farmasi dan obat-obatan karena memiliki sifat terapeutik, seperti mengobati rematik dan penyakit lain serta penyembuhan penyakit bisul perut (Tsukiyama et al., 2002).

Meskipun kalkon tersebar diberbagai famili tanaman, namun jumlahnya terbatas dibanding dengan senyawa flavoniod lain karena senyawa ini termasuk dalam kategori minor flavonoid dan persentasenya dalam tumbuhan juga kecil serta variasi strukturnya relatif sedikit. Oleh karena itu, untuk mendapatkan kalkon dalam jumlah yang cukup serta variasi struktur yang banyak maka hanya dapat dilakukan dengan sintesis di laboratorium.

Secara umum, kalkon dapat disintesis dengan berbagai metode salah satunya adalah melalui reaksi kondensasi suatu aldehid aromatik dengan suatu keton

\footnotetext{
*Telp: 08127515110

Email: ym_eryanti @yahoo.com
}

aromatik baik dalam kondisi asam maupun basa. Reaksi ini dikenal dengan reaksi kondensasi aldol atau lebih khusus reaksi kondensasi Claisen-Schmidt (Palleros, 2004). Reaksi kondensasi aldol sangat banyak digunakan dalam reaksi pembentukan ikatan karbon-karbon, karena reaksinya sederhana, bahan baku mudah didapat dan juga ramah lingkungan (green chemistry).

Metoda ini juga dapat digunakan untuk membuat senyawa yang mempunyai aktifitas biologis yang sama seperti kalkon yaitu turunan kurkumin. Selain alasan diatas, daya tarik metoda ini adalah karena memungkinkan dilakukan melalui pendekatan kimia kombinatorial. Melalui pendekatan ini dapat dibuat turunan kalkon dengan berbagai variasi substituen pada kedua cincin benzen sehingga menghasilkan perpustakaan molekul kalkon. Perpustakaan molekul kalkon akan berguna untuk menjelaskan antara struktur kimia denagan aktivitas biologinya dan sangat berguna untuk tujuan terapeutik seperti mencari aktivitas biologis tertentu misalnya antimikroba, antikanker, antiinflamasi dan lain-lain.

\section{BAHAN DAN METODE}

Alat dan bahan. Bahan yang digunakan adalah 2'-hidroksi asetofenon (Aldrich), benzaldehid (Wakapure), sinamaldehid (Fisons), 4'dimetilaminobenzaldehid (Merck), diklorometana, 
heksana, eter, kloroform, barium hidroksida oktahidrat, etanol absolut, etanol $96 \%$, plat klt GF $_{254}$ silika gel, PDA (potato dextrosa agar), NB (nutrient broth), NA (nutrient agar) dan WP (water peptone). Mikroba yang digunakan adalah bakteri Eschercia coli, Basilus subtilis, dan fungi Rizopus oryzae.

Alat yang digunakan adalah labu bulat, pengaduk magnit, hot plate, kondensor, corong buchner, termometer, neraca analitis, lampu ultra violet, alat penentu titik leleh Fisher Jhon, spektrofotometer IR merk Shimadzu tipe IR Prestige-21, spektrofotometer UV-Visible merk Hitachi U-2001, spektrofotometer NMR merk JOEL tipe ECA 500 dengan frekwensi $500 \mathrm{MHz}$ untuk proton dan $125 \mathrm{MHz}$ untuk karbon dan alat-alat gelas yang umum digunakan di laboratorium.

Sintesis kalkon Campuran turunan aldehid aromatik (2a, 2b dan 2c) 0,0105 mol, turunan 2hidroksiasetofenon (1) 0,01 mol, barium hidroksida oktahidrat $(0,0055 \mathrm{~mol})$, dan $10 \mathrm{ml}$ etanol absolut dimasukkan ke dalam labu bulat yang telah dilengkapi pengaduk magnet dan kondensor refluk. Campuran reaksi dibiarkan selama 2,5 jam hingga didaptkan padatan, kemudian dinginkan dan dilarutkan dengan $50 \mathrm{ml} \mathrm{HCl}$ 0,1 N. Endapan yang diperoleh dicuci dengan $50 \mathrm{ml}$ aquadest, kemudian $50 \mathrm{ml}$ heksana dan dikeringkan pada suhu $40^{\circ} \mathrm{C}$ selama 24 jam. Rekristalisasi dilakukan dengan menggunakan etanol absolut menghasilkan senyawa 3a 3b dan 3c.
Uji antimikroba, Uji aktivitas antibakteri Kedalam cawan petri yang sudah distrilisasi, masukan $1 \mathrm{ml}$ larutan NB yang berisi biakan bakteri, kemudian tambahkan 15 ml NA (Nuttien Agar) digoyang-goyang agar bakteri tersuspensi merata. Media NA dibiarkan memadat, kemudian diletakan kertas cakram (diameter $6 \mathrm{~mm}$ ) yang telah dibubuhi sampel yang akan diuji dengan konsentrasi sampel $10 \%(\mathrm{~b} / \mathrm{v})$ dalam etanol absolute dan sebagai control adalah kertas cakram yang dicelupkan pada etanol tersebut. Selanjutnya diinkubasi dalam incubator pada suhu $37^{\circ} \mathrm{C}$ dengan membalikan cawan petri. Diameter daerah bening disekitar cakram diukur setelah inkubasi selama 24 jam.

Uji aktivitas antijamur, Larutan water peptone yang mengandung spora jamur dipipet sebanyak $1 \mathrm{ml}$ kedalam cawan petri. PDA dipanaskan sampai mencair kemudian didinginkan pada suhu $50^{\circ} \mathrm{C}$ dan dituangkan sebanyak $15 \mathrm{ml}$ kedalam cawan petri. PDA dibiarkan memadat dan diatasnya diletakan kertas cakram yang telah dicelupkan kedalam sampel yang akan diuji dengan konsentrasi $10 \%(\mathrm{~b} / \mathrm{v})$ dalam etanol absolut dan kertas cakram yang dicelupkan kedalam larutan etanol absolute sebagai control Cawan petri dibalikan dan diinkubasi pada suhu $37^{\circ} \mathrm{C}$. Diameter daerah bening disekitar cakram diukur setelah diinkubasi selama 24 jam.

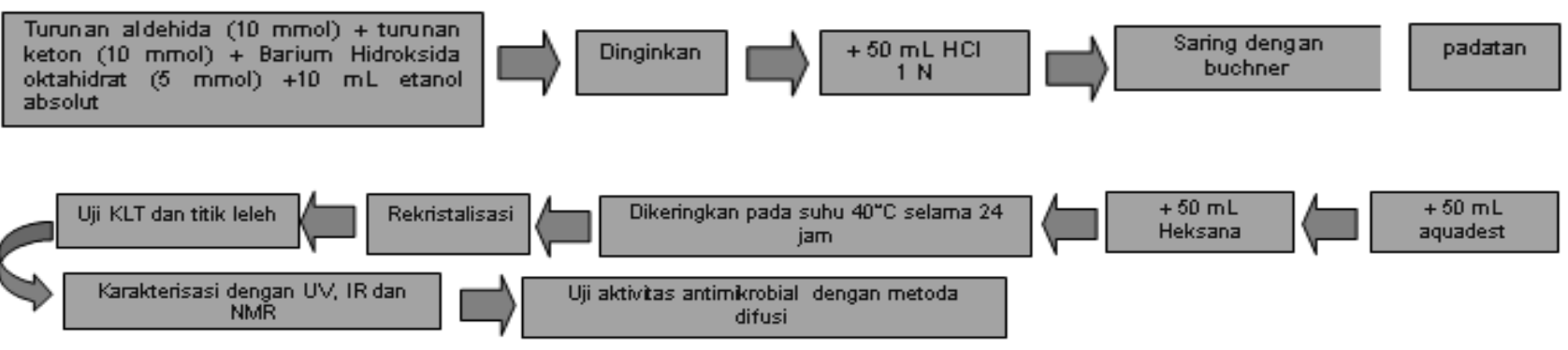

Skema 1. Bagan alir sintesis senyawa kalkon

\section{HASIL DAN PEMBAHASAN}

Hasil 1. 2'-hidroksi kalkon (3a)

- Padatan berwarna kuning dengan berat sebanyak $0,9639 \mathrm{~g}$

- Rendemen $43 \%$.

- Titik leleh : $86-87^{\circ} \mathrm{C}$

- Rf : 0,64 (diklorometana : heksana = 4:1)

- $\quad$ Spektrum UV : $\ddot{e}_{\text {Maks }} \mathrm{nm}(\mathrm{A})=314,4 ; 221,8 ; 204,6$ 254,$1 ; 212,2 \mathrm{~nm}$ pergeseran panjang gelombang pada 308,$2 ; 243,4 \quad ; 207,2 ; 251,0 ; 239,6 \mathrm{~nm}$

- $\quad$ Spektrum IR $\left(\mathrm{cm}^{-1}\right) 3055,24 ; 3045,24 ; 3026,31$ $\mathrm{cm}^{-1} ; 1639,49 ; 1573,91$ dan 1485,19

- $\quad$ Spektrum ${ }^{1} \mathrm{H}$ NMR (ä) 7,92 (1 H,d, J=15,3 Hz) ä 7,$67 ;(1 \mathrm{H}, d, J,=15,3 \mathrm{~Hz})$; ä 7,67 ; ä 6,95; 7,44 ; 7,50 ; dan 7,93; ä 12,8293.

- Spektrum ${ }^{13} \mathrm{C}$ NMR (ä) 193,9 ; ä 163,76 ; ä 145,67 ; 119,05 ; ä 129,84 ; ä 128,85 ; ä 129,24 ; 120,27 ; 118,83;136,61; 120,18;131,12. 
<smiles>O=C(/C=C/c1ccccc1)c1ccccc1O</smiles>

2. (2Z, 4Z)-1-(2-hidroksifenil)-5-fenilpenta-5-2,4dien-1-on (3b)

- Padatan kuning pekat dengan berat sebanyak $2,1442 \mathrm{~g}$

- Rendemen sebesar $85,76 \%$.

- Titik leleh: $151-153^{\circ} \mathrm{C}$

- Rf : 0,62 (diklorometana : heksana = 4:1).

- Spektrum UV : $\ddot{e}_{\text {Maks }} \mathrm{nm}(\mathrm{A})$ á 257,$0 ; 241,8 ; 207,8$ $; 250,5 ; 227,4 \mathrm{~nm}$ pergeseran panjang gelombang pada 238,$8 ; 208,8 \mathrm{~nm}$

- Spektrum IR $\left(\mathrm{cm}^{-1}\right): 3051,39 ; 305,96 ; 3005,10$; $1633,71 \mathrm{~cm}^{-1} ; 1566,20 ; 1489,053285$.

- Spektrum ${ }^{1} \mathrm{H}$ NMR (ä) 7,$73 ;(1 \mathrm{H}, d, J=25,05 \mathrm{~Hz})$; ä 7,$22 ;(1 \mathrm{H}, d, J,=14,7 \mathrm{~Hz}) \quad ; 7,02 ; 6,93$. (ä) 7,$53 ; 7,35$ (ä) 7,06; 7,47 ; 7,85 (ä) 12,90.

- Spektrum ${ }^{13} \mathrm{C}$ NMR (ä) 193,8734 ; (ä) 163,7418 ; (ä) 129,$09 ; 145,71 ; 120,17$; 129,69. (ä) 127,62 ;

(ä) 123,61 ; (ä) 126,$84 ; 118,98 ; 118,83 ; 96,9$; 143,$12 ; 118,76 ; 136,10$

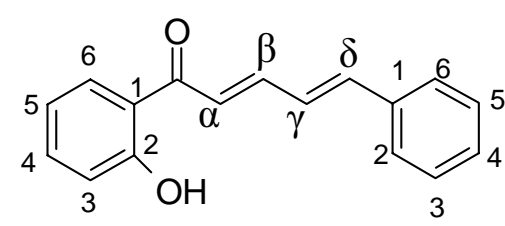

3. 2'-hidroksi-4-dimetilamino kalkon (3c)

- Padatan berwarna merah dengan berat sebanyak $0,2242 \mathrm{~g}$

- Rendemen sebesar 4,19\%.

- Titik leleh : $172-173^{\circ} \mathrm{C}$

- Rf : 0,4 (eter: heksana =2:3).

- Spektrum UV $\ddot{e}_{\text {Maks }} \mathrm{nm}(\mathrm{A}): 326,4 ; 273,2$ dan 205,6 ;325,6;309,6;221,5nm pergeseran pada panjang gelombang 328,$0 ; 256,4$ dan 206,8 ; 323,2 ;305,0; 228,6nm

- Spektrum IR $\left(\mathrm{cm}^{-1}\right): 2910,58 ; 2856,58 ; 1620,21$; 1597,$06 ; 1575,84 ; 1523,76 ; 3285$

- Spektrum ${ }^{1} \mathrm{H}$ NMR (ä) 3,06 ; (ä) 7,92 (1 H,d, $J=$ $15,90 \mathrm{~Hz})(\mathrm{ä}) 7,46(1 \mathrm{H}, d, J,=15,25 \mathrm{~Hz})(\mathrm{a}) 7,58$; 6,70 (ä) 7,$93 ; 7,00 ; 7,92$. (ä) 13,21 .

- $\quad$ Spektrum ${ }^{13} \mathrm{C}$ NMR (ä) 193,68 (ä) 163,65 (ä) 118,$66 ; 146,72$; (ä) 124,70 (ä) 129,53; 111,96 ; (ä) 152,$49 ;$ (ä) 40,31 .

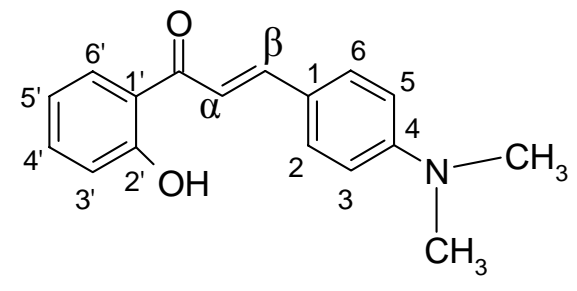

3. Hasil uji aktivitas antimikroba

Tabel 1. Perpustakaan Molekul Kombinatorial Hipotetik

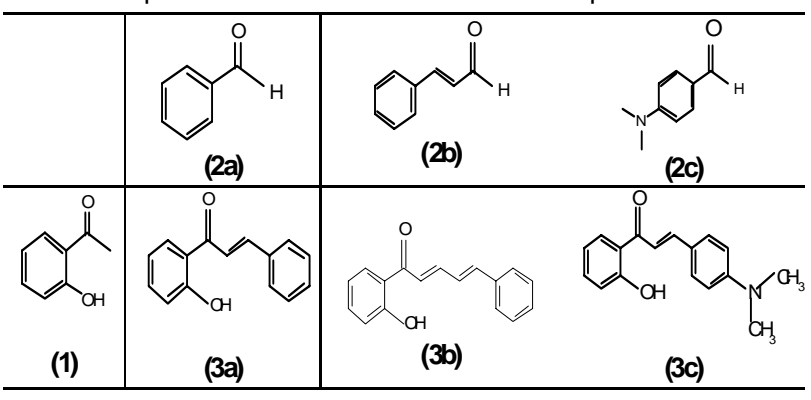

Uji aktivitas antimikroba yang dilakukan pada ketiga senyawa $3 a, 3 b$ dan $3 c$ dengan konsentrasi 10 , 20, 3 Diameter daerah hambatan $(\mathrm{mm}) \quad$ ya terhadap

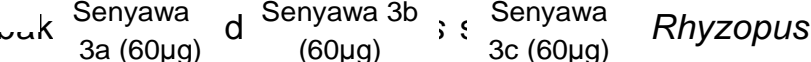

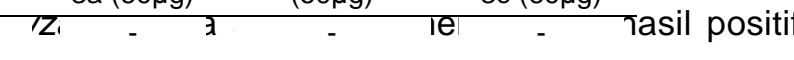
nc - je - $\quad$ - $\quad$ sk 12 ki aktivitas kalkon (3c) pada konsentrasi 60 ì g terhadap bakteri B.subtilis. Hal ini dibuktikan dengan adanya zona bening disekitar kertas cakram dengan diameter $12 \mathrm{~mm}$.

Mekanisme pembentukan senyawa turunan kalkon merupakan reaksi kondensasi antara suatu keton aromatik dengan suatu aldehid aromatik dalam suasana asam atau basa. Pada penelitian ini, kami menggunakan barium hidroksida sebagai basa, dengan cara ini memungkinkan untuk membuat turunan 2'-hidroksi kalkon dengan rendemen yang cukup baik yaitu antara $43-85 \%$ kecuali untuk senyawa 3c (4,19\%). Hal ini disebabkan karena dalam suasana basa, elektron bebas dari nitrogen melakukan resonansi ke dalam cincin aromatik sehigga mengurangi reaktivitas gugus karbonil (Wade 2006). Metoda ini pada prinsipnya cukup sederhana karena tidak memerlukan work up yang rumit, hanya dengan penyaringan dan pencucian padatan yang diperoleh. Salah satu hambatan yang ditemui adalah munculnya 
Tabel 2. Spektrum UV dan IR Senyawa (3a), (3b), (3c)

\begin{tabular}{|c|c|c|c|c|c|}
\hline Spektrum & Senyawa (3a). & \multicolumn{3}{|c|}{ Senyawa (3b) } & Senyawa (3c) \\
\hline$\overline{U V}: \lambda_{\text {Maks }} \mathrm{nm}(\mathrm{A})$ & 314,$4 ; 221,8 ; 204,6$ & 257,$0 ; 24$ & $8 ; 207,8$ & & 326,$4 ; 273,2 ; 205,6$. \\
\hline$\Lambda_{\text {Maks }}+\mathrm{NaOH}$ nm (A) & 308,$2 ; 243,4 ; 207,2$ & 238,$8 ; 20$ & & & 328,$0 ; 256,4 ; 206,8$ \\
\hline $\mathrm{IR}\left(\mathrm{cm}^{-1-}\right)$ & 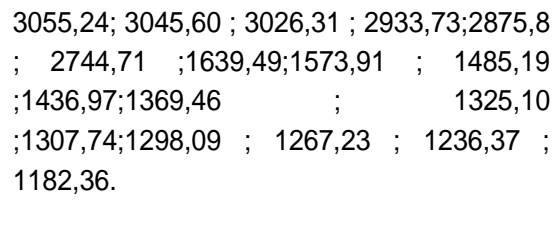 & $\begin{array}{l}3051,39 ; \\
1633,71 ; \\
1489,05 ; \\
1348,24 ; \\
1278,81 ; \\
1201,65\end{array}$ & $\begin{array}{l}3035,96 \\
1606,70 \\
1444,68 \\
1338,60 \\
1246,02\end{array}$ & $\begin{array}{l}3005,10 ; \\
1566,20 ; \\
1371,39 \\
1301,95 \\
1228,66\end{array}$ & $\begin{array}{l}2910,58 ; 2856,58 ; 2819,93 ; \\
1620,21 ; 1597,06 ; 1575,84 ; \\
1523,76 ; 1487,12 ; 1435,04 ; \\
1408,04 ; 1379,10 ; 1340,53 ; \\
1311,59 ; 1276,88 ; 1230,58 ; \\
1205,51 ; 1176,58 ; 1157,29 .\end{array}$ \\
\hline
\end{tabular}

Tabel 3. Interpretasi data ${ }^{1} \mathrm{H}$ dan ${ }^{13} \mathrm{C}$ NMR Senyawa (3a), (3b), (3c

\begin{tabular}{|c|c|c|c|c|c|c|}
\hline & \multicolumn{2}{|c|}{ Senyawa (3a) } & \multicolumn{2}{|c|}{ Senyawa (3b) } & \multicolumn{2}{|c|}{ Senyawa (3c) } \\
\hline No. atom C & $\bar{\delta}_{H}(\mathrm{ppm})$ & $\delta_{\mathrm{c}}(\mathrm{ppm})$ & $\bar{\delta}_{H}(\mathrm{ppm})$ & $\delta_{C}(p p m)$ & $\delta_{H}(\mathrm{ppm})$ & $\delta_{\mathrm{C}}(\mathrm{ppm})$ \\
\hline 1 & - & 134,76 & 1 & 136,44 & & 124,70 \\
\hline $2 / 6$ & 7,66 & 128,85 & 7,53 & 123,61 & 7,58 & 129,53 \\
\hline $3 / 5$ & 7,43 & 129,84 & 7,35 & 127,62 & 6,70 & 111,96 \\
\hline 4 & 7,03 & 129,24 & 7,06 & 126,84 & - & 152,49 \\
\hline $\mathrm{C} \alpha$ & $7,67(d, J=15,3)$ & 119,05 & $7,73(d, J=12,8)$ & 129,09 & $\begin{array}{c}7,46(d, J=15,25 \\
H z)\end{array}$ & 118,66 \\
\hline $\mathrm{C} \beta$ & $\begin{array}{c}7,92(d, J= \\
15,3)\end{array}$ & 145,67 & $7,22(d, J=14,7)$ & 145,71 & $\begin{array}{c}7,92(d, J=15,90 \\
H z)\end{array}$ & 146,72 \\
\hline $\mathrm{Cy}$ & - & - & 7,02 & 120,17 & - & - \\
\hline $\mathrm{C} \delta$ & - & - & 6,93 & 129,69 & - & - \\
\hline $\mathrm{C}=\mathrm{O}$ & - & 193,92 & - & 193,87 & - & 193,68 \\
\hline 1 ' & - & 120,27 & - & 118,98 & - & 120,56 \\
\hline 2' & - & 163,76 & - & 163,74 & - & 163,65 \\
\hline $3^{\prime}$ & 6,95 & 118,83 & 7,06 & 96,9 & 7,93 & 114,43 \\
\hline $4^{\prime}$ & 7,44 & 136,61 & 7,39 & 143,12 & 7,00 & 135,84 \\
\hline 5 & 7,50 & 120,18 & 7,47 & 118,76 & 7,46 & 118,74 \\
\hline $6^{\prime}$ & 7,93 & 131,12 & 7,85 & 136,10 & 7,92 & 131,04 \\
\hline 2'-OH & 12,81 & - & 12,90 & - & 13,21 & - \\
\hline $\mathrm{N}\left(\mathrm{CH}_{3}\right)_{2}$ & & & & & 3,06 & 40,31 \\
\hline
\end{tabular}

endapan yang yang memadat pada saat refluk sehingga mengurangi rendemen reaksi. Bila senyawa yang diperoleh belum murni maka perlu dilakukan pemisahan lebih lanjut melalui kolom kromatografi sederhana. Melalui pendektan kimia kombinatorial telah berhasil disintesis 3 turunan kalkon seperti Tabel 1.

Spektrum UV dari senyawa kalkon 3a-3b pada umumnya memperlihatkan adanya 2 pola pada serapan maksimum yaitu 203-205 nm untuk cincin turunan asetofenon dan serapan maksimum 251-273 nm untuk cincin aldehid. Serapan maksimum utama untuk cincin asetofenon yang tersubtitusi adalah sekitar 203-205 nm, bila ada subtituen hidroksi pada posisi 2 maka muncul serapan lain sekitar 255-279 nm. Serapan maksimum kedua pada 251-303 nm berhubungan dengan serapan dari turunan benzaldehid yang bisa mengalami eksistensi sekitar $150 \mathrm{~nm}$ terutama karena adanya gugus dimetilamino (3c), serapan maksimum muncul pada panjang gelombang $420 \mathrm{~nm}$. Serapan maksimum ini menunjukkan bahwa senyawa tersebut memiliki ikatan rangkap terkonjugasi dengan gugus ausokrom dimetilamino. Serapan maksimum lain yang juga khas adalah turunan sinamldehid ( $3 b$ ) yaitu $241 \mathrm{~nm}$, adanya penambahan sekitar $70 \mathrm{~nm}$ dari serapan turunan benzaldehid berhubungan dengan penambahan satu ikatan rangkap.

Spektrum IR turunan kalkon pada umumnya menunjukkan frekuensi vibrasi khas untuk gugus $\mathrm{C}=\mathrm{O}$ sekitar $1620-1660 \mathrm{~cm}^{-1}$ dan gugus $\mathrm{C}=\mathrm{C}$ sekitar 1536 $1599 \mathrm{~cm}^{-1}$ dan gugus fenolik pada bilangan gelombang $3215 ; 3420 \mathrm{~cm}^{-1}$. Frekuensi vibrasi OH untuk senyawa 3a-b bergeser ke bilangan gelombang sekitar 2830-2950 $\mathrm{cm}^{-1}$ hal ini disebabkan karena ada ikatan hidrogen intramolekuler antara gugus $\mathrm{OH}$ dan keton. Data lengkap UV dan IR dapat dilihat dari Tabel 2.

Spektrum ${ }^{1} \mathrm{H}$ NMR turunan kalkon pada umumnya menunjukkan adanya pergeseran kimia yang khas yaitu munculnya puncak doublet dengan konstanta kopling sekitar 15-16 Hz yang berhubungan dengan adanya proton C-á (7.22-7.67 ppm) dan C-â (7.49-7.94). Demikian pula untuk ${ }^{13} \mathrm{C}$ NMR C-á (125-131 ppm) dan C-â (35-146 ppm). Spektrum NMR untuk 2'hidroksikalkon 3a-3b umumnya juga menunjukkan sinyal khas pada tipe proton C-á dan C-â yaitu munculnya sinyal dengan doublet dengan konstanta kopling antara 15-16 Hz. Hal ini berhubungan dengan bentuk konfigurasi trans $(E)$ dari kedua proton tersebut. Disamping itu juga ada sinyal khas dari gugus $\mathrm{OH}$ pada 
pergeseran kimia 12,9 sampai 13,1 ppm. Data lengkap ${ }^{1} \mathrm{H}$ NMR dan ${ }^{13} \mathrm{C}$ NMR untuk senyawa $3 a-3 \mathrm{c}$ dapat dilihat pada Tabel 3.

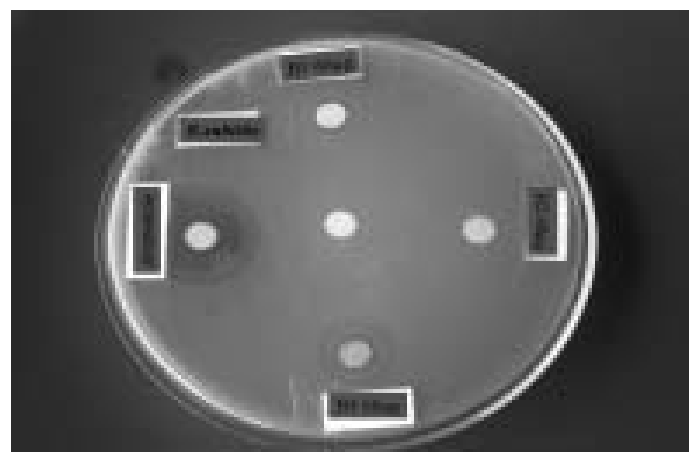

Gambar 1. Pembentukan daerah hambatan terhadap pertu,buhan B. subtilis

Uji antimikroba terhadap bakteri E.coli dan B.subtilis serta jamur Rhyzopus oryzae, hanya satu yang memberikan hasil positif yaitu pada konsentrasi $60 i ̀ g$ dengan diameter daerah hambatan $12 \mathrm{~mm}$ untuk senyawa 2'-hidroksi-4-dimetilamino kalkon (3c) terhadap bakteri B.subtilis dapat dilihat pada Gambar 1. Hal ini mungkin disebabkan karena adanya gugus aktif pada senyawa 3c yang mampu merusak dinding sel. Sedangkan uji aktivitas terhadap senyawa $3 a$ dan $3 c$ tidak menunjukan adanya hambatan terhadap pertumbuhan bakteri dan jamur pada semua konsentrasi. Hal ini mungkin disebabkan karena gugus fungsi yang ada pada senyawa tersebut tidak bisa menghambat pertumbuhan mikroba.

\section{KESIMPULAN.}

Senyawa turunan kalkon dapat disintesis melalui reaksi kondensasi aldol dari suatu keton aromatik dan aldehid aromatik dengan menggunakan katalis basa. Adanya gugus amino yang terletak pada posisi para dari aldehid aromatik menyebabkan rendemen yang dihasilkan sangat kecil. Hal ini dikarenakan gugus amino bersifat sebagai pendorong elektron. Efek resonansi ini membuat gugus karbonilnya lebih kaya elektron sehingga akan sulit untuk diserang oleh nukleofil.

Senyawa turunan kalkon yang positif memberikan aktivitas antimikrobial adalah senyawa 2'hidroksi-4dimetilamino kalkon.

\section{UCAPAN TERIMAKASIH}

Program Higher Education InstitutionImplementation Unit (HEI-IU) Indonesian Managing Higher Education for Relevance and Efficiency (IMHERE) UNRI IBRD Loan No. 4789-IND dan IDA Loan No. 4077-IND dengan Nomor Kontrak 141/RG//-MHERE/ UNRI/2007.

\section{DAFTAR PUSTAKA}

Alam, S. 2004. "Synthesis antibacterial and antifungal activity of some derivates of 2-phenyl-chromen-4-one". J. Chem. Sci. 116: 325-331.

Harborne, J.B. 1994. The Flavonoids Advances In Research Since 1986. Chapman and Hall: London

Hayashi, A., Gillen, A. \& Loot, J.R. 2000. Effects of daily oral administration of quercetin chalcone and modified citrus pectin on implated colon-25 tumor growth in balb-c mice. Alternative Medicine Review. 1-5.

Palleros, D.R. 2000. Experimental Organic Chemistry. John Willey and Sons, New York.

Tsukiyama, R.I., Katsura, H., Tokuriki, N. \& Kobayashi, M. 2002. Antibacterial Activity of Licochalcone A against SporeForming Bacteria. J. American Society for Microbiology. May 2002. 1226-1230.

Usman, H., Hakim, E.H., Achmad, S.A., Harlim, T., Jalaluddin, M.N., Syah, Y.M., Juliawati, L.D., Makmur, L. \& Katajima, M. 2005. 2',4'-dihidroksi-3',5',6'-Trimetoksi Kalkon suatu Senyawa Antitumor dari Kulit Batang Tumbuhan Cryptocarya costata (Lauraceae). Jurnal Matematika dan Sains. 10: 97100.

Vender, B., Haemers, A. \& Vlieunek, A. J. 1993. In bioactive natural products; detection and structural determination. Ed.Collegate, S.M and Molyneux. CRC Press. 17: 186. 343355. 